\title{
Studies of the Biosynthesis of Protein and Ribonucleic Acid in HeLa Cells Infected with Poliovirus ${ }^{1}$
}

\author{
W. Wilbur Ackermann, Philip C. Loh, and Francis E. Payne \\ Department of Epidemiology and Virus Laboratory, School of Public \\ Health, University of Michigan, Ann Arbor, Michigan
}

Accepted November 5,1958

\begin{abstract}
The amounts of protein, RNA (ribonucleic acid), virus, and the rate of incorporation of $\mathrm{P}^{32}$ into $\mathrm{RNA}$ were determined in various subcellular fractions of HeLa cells at various times during a single sequence of infection with poliovirus. From these data interpretations are drawn concerning the biosynthesis at the cellular level of protein and RNA which are induced by virus infection. Within 1 hour after the initiation of infection, there is a detectable accumulation in the cellular cytoplasm of newly synthesized protein and RNA. The synthesis of protein continues at a constant rate until the seventh hour of infection. RNA in the cytoplasm increases at a constant rate until the fourth hour, at which time the rate is markedly enhanced, and the first virus, as infectious activity, appears in the cytoplasmic fraction. The synthesis of RNA stops by the sixth hour. Virus accumulates at an increasing rate in the cytoplasm between the fourth and seventh hours. At the seventh hour, $99 \%$ of the virus formed is present in the intracellular state. From the amounts of nucleic acid and protein produced, their distribution relative to virus among the various subcellular fractions, and from the nucleotide composition of the RNA, it was concluded that the major portion of the newly formed materials was not virus.
\end{abstract}

\section{INTRODUCTION}

There have been several studies of phosphorus or nucleic acid metabolism in poliovirus-infected tissue culture cells. Becker et al. (1958) have observed an increased incorporation of $\mathrm{P}^{32}$ into human amnion cells following infection. Similarly, Miroff et al. (1957) found an increased incorporation of radioactive phosphorus into the total nucleic acids of HeLa cells during the first 2 hours of infection with poliovirus. In the same cell-virus system Goldfine et al. (1958) determined, at 11 hours

I This work was supported by a grant from the National Foundation for Infantile Paralysis. 
after infection, the incorporation of label from $\mathrm{C}^{14}$-cytidine into cellular ribonucleic acid (RNA) and deoxyribonucleic acid (DNA). These previous studies have been restricted in some instances to particular times during the infectious cycle and in others to particular fractions of the infected cells. The need for correlation of observations on various metabolic fractions and virus at several times during a single cycle of infection is apparent in our previous publications (Loh et al. 1957; Maassab et al., 1957). It was reported that RN $\Lambda$ accumulates in the cytoplasm of HeLa cells during the infectious cycle in amounts which were in excess of that which could be virus. By the sixth hour of infection this increase was maximal but only slight changes occurred in the amounts of RNA and DNA of the nucleus. However, the incorporation of radioactive phosphate from the medium into nuclear RNA indicated there was extensive "turnover" of the fraction which may represent synthesis despite lack of net increase. In these studies (Loh et al., 1957; Maassab et al., 1957) the amount of RNA was calculated from the phosphorus content of the isolated RNA.

In the present paper data are presented confirming that the abovenoted increase in RNA phosphorus really reflects increases in nucleotide polymers. Observations on the poliovirus-infected cells have been extended to a study of the cellular protein. The nature of the newly formed materials was investigated by nucleotide analysis of the RNA and by determining the distribution of protein, infectious virus, and ribonucleic acid among the various cytoplasmic subcellular components. The kinetics of each were followed during a single sequence of infection. The data indicate that after infection of cells a considerable synthesis continues of materials which do not constitute virus and might not be destined to be virus.

\section{MATERIALS AND METHODS}

Virus. The Mahoney strain of type 1 poliovirus was used in these studies. It has undergone approximately twenty serial passages in HeLa cells.

Cell culture. The host cells used in all experiments were derived from strain HeLa. They were obtained from Dr. J. T. Syverton and are kept in continuous passage. Only 5-day-old cultures were used. The procedure for preparation and maintenance of the cultures has been described elsewhere (Maassab et al., 1957).

Maintenance medium. The medium used for the study of virus multi- 
plication was composed of $10 \%$ equine serum (ES) and $90 \%$ Scherer's maintenance solution (MS) (Scherer, 1953).

Isotopic phosphorus. Sterile solutions of $\mathrm{P}^{32}$ in dilute $\mathrm{HCl}$ with specific activity of 60 to $90 \times 10^{3}$ millicuries per gram were obtained from Oak Ridge National Laboratories. A sufficient amount of $\mathrm{P}^{32}$ was introduced into experimental cultures to give a final activity of 125 microcuries per culture. Both the infected and control cultures were exposed to $\mathrm{P}^{32}$ for the last half hour of any particular infectious period under study. The preparation of the samples for determination of radioactivity has been reported previously (Maassab et al., 1957).

Fractionation of cells. Before homogenization all cultures were washed three times with buffered saline at room temperature. The cells were scraped from the wall of the culture bottle into a cold solution of $0.1 \mathrm{M}$ sodium chloride and $0.05 M$ sodium citrate, $\mathrm{pH} \mathrm{7.2.} \mathrm{The} \mathrm{cells} \mathrm{were}$ counted in a hemocytometer and were disrupted with a Potter-Elvehjem homogenizer (Teflon pestle). The nuclei were sedimented with a force of $581 \mathrm{~g}$ at $0^{\circ}$ (refrigerated International Centrifuge, $2000 \mathrm{rpm}$ for 10 minutes, International anglehead rotor no. 824). The nuclear residue was homogenized twice more and the pooled supernatants were the cytoplasmic fraction. This was further fractionated in certain experiments, by differential centrifugation with a Spinco model L ultracentrifuge. Three fractions were obtained under the following conditions: fraction $\mathrm{I}$, the sediment after $6600 \mathrm{~g}$ for 20 minutes; fraction II, the sediment after $41000 \mathrm{~g}$ for 1 hour; fraction III, the supernatant fluid above fraction II (Hogeboom and Schneider, 1955).

Ribonucleic acid. The cRNA (cytoplasmic ribonucleic acid) was isolated from cytoplasmic fractions by precipitation of the nucleoprotein with cold TCA (trichloroacetic acid) followed by cleavage of the nucleoprotein with hot TCA as described by Schneider (1945). The RNA so obtained did not give a positive test for deoxyribose (diphenylamine reaction). The amount of RNA in the hot TCA fraction was determined by phosphorus analysis.

Nucleotide analysis. For the study of the nucleotide composition, the isolated cytoplasmic ribonucleoprotein obtained by cold TCA precipitation and extraction with ether and alcohol, was hydrolyzed to a mixture of the component nucleotides by the method of Volkin and Carter (1951). The mixture was separated by anion exchange chromotography as described by Hurlbert et al. (1954) using a Dowex (formate) column. 
The quantity of individual nucleotides eluted was estimated for their optical density at a wavelength of $2600 \mathrm{~A}$.

Phosphorus. The phosphorus content of the nucleic acid fractions was determined by the method of Fiske and SubbaRow (1925).

Protein. The protein of various cell fractions was determined by measurement of nitrogen in the washed residue of the cold TCA precipitate following extraction of lipids and nucleic acids.

Nitrogen. The nitrogen content of the various fractions was estimated with the procedure described by Koch and McMeekin (1924).

Virus assays. The amounts of intracellular virus were determined by assay of the citrate-saline extracts of the subcellular fractions using the plaque technique of Dulbeceo and Vogt (1954) modified for use in HeLa cells by Payne et al. (1958).

\section{EXPERIMENTAL}

The procedure of infecting the cell cultures followed one design. Monolayers of cells were exposed to high concentrations of virus for an interval of 1 hour. The multiplicity of exposure per cell was approximately 100 . During the period of exposure nearly all cells were infected as judged by induction of cytopathic effect. The completeness of infection was verified by supporting experiments on the kinetics of the initiation of infection (Payne et al., 1958) and on the release of virus (Maassab et al., 1957). The biochemical observations recorded concern a single cycle of infection.

In a typical experiment a series of bottle cultures incubated 18 hours with maintenance medium, each containing 4 to $6 \times 10^{6}$ cells, was rinsed twice with $5 \mathrm{ml}$ of BSS (balanced salt solution) and replaced with $4 \mathrm{ml}$ of maintenance medium (MS90Es10). Two milliliters of undiluted tissue culture fluid (MS90ES10) containing poliovirus were introduced to give a final concentration of $1 \times 10^{8}$ PFU per milliliter. The cultures were incubated at $37^{\circ}$ for 1 hour, washed three times with $10 \mathrm{ml}$ of BSS to remove the residual virus, and overlaid with $7 \mathrm{ml}$ of MS90ES10. The cells were then replaced in the incubator until the desired period of infection was achieved. In certain experiments where radioactive phosphorus was used, the isotope was introduced at the last half hour of the infectious period under study. The amount of $P^{32}$ introduced was sufficient to give a final activity of 125 microcuries per culture.

At the end of any particular period of infection, the cultures were 
washed three times with $15 \mathrm{ml}$ of buffered saline and were drained well. The cells were removed with the aid of a rubber policeman into a cold citrate-saline solution. Cell fractionation and subsequent chemical analyses were carried out as described in the section Materials and Methods.

\section{RESULTS}

Amounts of Nucleotides in Cytoplasmic RNA of Normal and Infected HeLa Cells

Our previous observation that there is a marked increase of cytoplasmic RNA in HeLa cells infected with poliovirus was confirmed and extended by the following experiment. RNA was isolated from the cytoplasmic fraction of normal cells and also from cells 6 hours after infection. Chromatographic fractionation of the hydrolyzate of these nucleic acids yielded only the usual four nucleotides of RNA. The number of micromoles of each nucleotide was determined and the values in Table 1 are given in micromoles per cell. There is approximately $150 \%$ more of each nucleotide in the cytoplasmic RNA of infected as compared to normal cells.

\section{Nucleotide Composition of RNA from Normal and Infected HeLa Cells}

The nucleotide composition of the RNA isolated from the cytoplasmic fraction of normal HeLa cells is very similar to that reported for RNA

\section{TABLE 1}

Amount of Each Nucleotide in Cytoplasmic RNA (cRNA) of Normal and INFECTED HeLA Cells ${ }^{a}$

\begin{tabular}{lccc}
\hline & \multicolumn{3}{c}{$\mu$ Moles of Nucleotide $\times 10^{-9}$ per cell } \\
\cline { 2 - 4 } Nucleotide & \multicolumn{1}{c}{ Normal } & Infected & $\Delta$ Nucleotide $^{b}$ \\
\hline Cytidylic acid & $11.26 \pm 3.4$ & $28.75 \pm 8.6$ & 17.49 \\
Adenylic acid & $7.4 \pm 1.9$ & $19.05 \pm 6.1$ & 11.65 \\
Guanylic acid & $16.05 \pm 3.1$ & $38.49 \pm 8.8$ & 22.44 \\
Uridylic acid & $8.41 \pm 1.7$ & $21.03 \pm 7.54$ & 12.62
\end{tabular}

a Samples for analysis were obtained from HeLa cells 6 hours after initiation of infection with poliovirus and from normal HeLa cells treated in the same manner without exposure to virus. Values recorded here are averages of data from five experiments.

${ }^{b} \Delta$ Nucleotide $=$ the difference between normal and infected cells in the amount of each nucleotide in the cRNA. 
TABLE 2

Nucleotide Composition of Cytoplasmic RNA (cRNA) in Normal and INFECTEd HeLa Cells ${ }^{a}$

\begin{tabular}{cccrr}
\hline & & \multicolumn{2}{c}{ Infected } & \\
\cline { 3 - 5 } Nucleotide & Normal & Observed & Calculated $^{b}$ & Virus $^{c}$ \\
\hline Cytidylic acid & $15.4 \pm 0.41$ & $15.3 \pm 1.14$ & 9.2 & 6.0 \\
Adenylic acid & 10.0 & 10.0 & 10.0 & 10.0 \\
Guanylic acid & $20.2 \pm 1.14$ & $19.8 \pm 1.13$ & 12.0 & 8.4 \\
Uridylic acid & $10.2 \pm 0.95$ & $10.9 \pm 0.51$ & 8.8 & 8.1 \\
\hline
\end{tabular}

${ }^{a}$ Relative values for the amounts of nucleotides in the cRNA of normal and infected cells were derived from data presented in Table 1 by assigning adenylic acid an arbitrary value of 10.0 . These values are for cells 6 hours after initiation of infection.

"The nucleotide composition of cRNA of infected cells was calculated assuming that a conservative minimal increase of $120 \%$ above normal would be entirely attributable to the RNA of poliovirus.

$c$ Data on the nucleotide composition of poliovirus type 1 (Mahoney) is from Schwerdt (1957).

isolated from other mammalian tissues in that it is rich in guanylic and cytidylic acids and poor in adenylic and uridylic acids. The molar values experimentally obtained are given in column 2 of Table 2 , where adenylate is expressed as 10 and relative values are assigned for the other nucleotides. The cytoplasmic RNA of infected cells was found to have a nucleotide composition (column 3, Table 2) which does not differ significantly from that of the normal cell. Values obtained by Schwerdt (1957) for the nucleotides of RNA from poliovirus, Mahoney strain, are recorded in column 5. Assuming that a $120 \%$ increment in RNA occurred in the infected cells and that this newly formed RNA was all of the viral type, the ratio of bases that would obtain from such a mixture of viral and ordinary cytoplasmic RNA was calculated (column 4 , Table 2). Such a composite would have been readily distinguished from the ordinary cytoplasmic RNA. Thus while viral RNA must be synthesized in the infected cell, the major portion of the newly formed RNA induced by virus infection is not of the viral type, but resembles more closely that of the ordinary cell cytoplasm.

\section{Analysis of the Subcellular Components of the Cytoplasm}

By 6-7 hours after infection, there is not only a massive accumulation in the cytoplasm of RNA but also of newly formed protein and of nearly 
all the virus which has appeared up to this time. If the chemically detectable protein and RNA constitute virus, then their distribution among the various subcellular elements of the cytoplasm should be parallel that of virus activity. At the sixth hour of infection, each of the three cytoplasmic fractions was isolated (as described in the section Materials and Methods) and analyzed for RNA, protein, virus, and the rate of incorporation of radioactive phosphate into RNA. The resulting data are recorded in Table 3.

The incorporation of $\mathrm{P}^{32}$ was allowed in the interval of 5.5 to 6.0 hours. At the sixth hour of infection, the experiment was terminated and RNA was isolated from each of three cytoplasmic fractions. $P^{32}$ was incorporated into the RNA of each fraction of the uninfected cell; however, the specific rates of incorporation by the fractions vary. Fraction III containing $75 \%$ of the cytoplasmic RNA is the least active (Table 3). After infection, there is an increase in the rates of incorporation by all fractions with that of fraction II being somewhat greater than that in I and III. It should be noted that the rate of incorporation of $\mathrm{P}^{32}$ by the infected cell is about twice that of the normal, and the net synthesis of cRNA is considerable whereas in the instance of the normal it is not detectable (Maassab et al., 1957).

The distribution of total RNA-phosphorus follows the same pattern as that seen with the radioactivity data. After infection there is an increase in all fractions, but by the sixth hour the greatest accumulation is

TABLE 3

Distribution of Protein-N and RnA-P in the Cytoplasmic Component of Normal, and Infected HeLa Cells ${ }^{a}$

\begin{tabular}{|c|c|c|c|c|c|c|c|}
\hline \multirow{3}{*}{$\begin{array}{l}\text { Cytoplasmic } \\
\text { fraction }\end{array}$} & \multicolumn{3}{|c|}{ Normal } & \multicolumn{4}{|c|}{ Infected } \\
\hline & \multicolumn{2}{|c|}{ RNA - P } & \multirow[b]{2}{*}{$\operatorname{mg~} \underset{10^{-10}}{\mathrm{~N}} \times$} & \multicolumn{2}{|c|}{ RNA - P } & \multirow[b]{2}{*}{$\underset{10^{-10}}{\operatorname{mg~} N} \times$} & \multirow[b]{2}{*}{$\begin{array}{l}\text { Virus } \\
\text { PFU }\end{array}$} \\
\hline & $\underset{10^{-4 b}}{\operatorname{Counts}} \times$ & $\underset{10^{-10}}{\mathrm{mg} \times}$ & & $\underset{10^{-4}}{\text { Counts }} \times$ & $\underset{10^{-10}}{\mathrm{mg} x}$ & & \\
\hline I & 1.45 & 1.95 & 59.74 & 2.73 & 3.21 & 91.52 & 15.5 \\
\hline II & 1.25 & 4.55 & 54.37 & 2.88 & 13.26 & 73.05 & 313.5 \\
\hline III & 4.45 & 20.38 & 248.19 & 6.54 & 25.51 & 379.87 & 54.5 \\
\hline
\end{tabular}

a Cytoplasm for ultracentrifugal fractionation was obtained from HeLa cells 6 hours after initiation of infection with poliovirus and from normal HeLa cells treated in the same manner without exposure to virus. All data are on a per cell basis and are from a single representative experiment.

${ }^{b}$ Cultures containing approximately $6 \times 10^{6}$ cells were exposed to 125 microcuries of $\mathrm{P}^{32}$ during the last 30 minutes of incubation. 
in fraction II $(191 \%)$ followed by fraction I $(65 \%)$ and fraction III $(25 \%)$. Likewise, all fractions show an increase in protein content. The largest accumulation is in fraction III, but the percentage increase in fractions I and III are the same and greater than in fraction II. The virus activity is found predominantly in fraction IT.

These data are more easily interpreted if one assumes that there is essentially no degradation of the original components of the cell after infection and that the increment of RNA and protein measured represents all of the newly formed material. The data for each fraction are expressed in this form in Table 4 under the headings $\Delta$ RNA-P and $\Delta$ protein- $N$ which represent the amounts of newly formed materials. It will be noted that the virus distribution only roughly parallels the $\Delta$ RNA-P and does not correspond at all to the $\Delta$ protein-N. Only $10 \%$ of the incremental protein is in fraction II while $81 \%$ of the virus is there.

Further, there is a characteristic ratio of protein-N to RNA-P for each of the components of the uninfected cell cytoplasm and also for the purified virus (the latter is taken from data of Schwerdt, 1957). Such a ratio can also be calculated for the material in each fraction newly

TABLE 4

The Ratio of $\Delta$ Protein-N to $\Delta$ RNA-P in the Cytoplasmic Components of Normal and Infected Hela Cello $\boldsymbol{S}^{a}$

\begin{tabular}{|c|c|c|c|c|c|c|c|c|}
\hline \multirow{3}{*}{$\begin{array}{c}\text { Cytoplasmic } \\
\text { fraction }\end{array}$} & \multicolumn{7}{|c|}{ Infected } & \multirow{3}{*}{$\begin{array}{c}\text { Normal } \\
\begin{array}{c}\text { Protein-N } \\
\text { RNA - P } \\
\text { ratio }\end{array}\end{array}$} \\
\hline & \multicolumn{2}{|c|}{ Virus } & \multicolumn{2}{|c|}{$\Delta \mathrm{RNA}-\mathrm{P}$} & \multicolumn{2}{|c|}{$\Delta$ Protein-N } & \multirow{2}{*}{$\begin{array}{c}\Delta \text { Protein-N } \\
: \Delta R N A-P \\
\text { ratio }\end{array}$} & \\
\hline & PFU & $\%$ & $\mathrm{mg} \times 10^{-10} \mid$ & $\%$ & $\mathrm{mg} \times 10^{-10}$ & $\%$ & & \\
\hline I & 15.5 & 4.04 & 1.26 & 8.3 & 31.78 & 17.3 & 25.14 & 30.63 \\
\hline II & 313.5 & 81.74 & 8.71 & 57.7 & 19.68 & 10.7 & 2.25 & 11.94 \\
\hline III & 54.5 & 14.21 & 5.13 & 33.9 & 131.68 & 71.9 & 25.76 & 12.17 \\
\hline Virus & & & & & & & $2.33^{b}$ & \\
\hline
\end{tabular}

a Cytoplasm for ultracentrifugal fractionation was obtained from HeLa cells 6 hours after initiation of infection and from normal cells treated in the same manner without exposure to virus. $\Delta \mathrm{RNA}-\mathrm{P}$ and $\Delta$ protein-N values were derived from data presented in Table 3 and represent the differences between normal and infected cell fractions in the amount of RNA-P and protein-N. All values are on a per cell basis.

${ }^{b}$ This ratio was calculated on the basis that poliovirus is $30 \%$ RNA and $70 \%$ protein. 
formed after infection (column 8, Table 4). A comparison of these values allows one to determine if the newly formed materials resemble the composition of the normal component with which it is associated, that of the virus, or if it is aberrant. The incremental material of fraction I has a ratio of protein-N to RNA-P which is similar to that of the normal fraction. This ratio for newly formed material associated with fraction II closely resembles that of poliovirus and not the normal cell component. Although this coincides with the presence in this fraction of the majority of the infectious virus, evidence presented in the earlier sections of this paper precludes the notion that all this new material is of viral nature. Fraction III of the infected cells in seen to contain an increment which is relatively rich in protein as compared to the normal component.

\section{Kinetics of Synthesis of RNA, Protein, and Virus}

The preceding sections describe the biochemical situation in the cell at the sixth hour of infection. The following experiment is concerned with the sequence of steps in time by which the situation developed. Replicate cultures of cells were analyzed at various times in the interval from the initiation of infection to the seventh hour. Uninfected control cultures which are pretreated with maintenance solution do not show changes in the amounts of DNA or RNA per cell nor in the number of cells during the experimental period. This is shown in Table 5, which contains data

\section{TABLE 5}

Cell Number and Nucleic Acid Composition of Uninfected Control Cultures at Various Times during INDIVIDUAL EXPERIMENTS ${ }^{a}$

\begin{tabular}{|c|c|c|c|c|c|}
\hline \multirow{2}{*}{ Expt. } & \multirow{2}{*}{$\operatorname{Time}(\mathrm{hr})^{b}$} & \multirow{2}{*}{ Cell count $\times 10^{5}$} & \multicolumn{3}{|c|}{$\mathrm{mg} \times 10^{-10}$ per cell } \\
\hline & & & cRNA - P & nRNA - P & DNA - P \\
\hline \multirow[t]{2}{*}{$A$} & 2 & 40.64 & 23.56 & 25.78 & 20.23 \\
\hline & 4 & 44.16 & 22.50 & 26.71 & 18.95 \\
\hline \multirow[t]{2}{*}{ B } & 2 & 51.87 & 26.46 & 32.70 & 18.70 \\
\hline & 4 & 49.56 & 25.51 & 31.80 & 21.35 \\
\hline \multirow[t]{2}{*}{$\mathrm{C}$} & 1 & 50.81 & 23.82 & 28.30 & 19.51 \\
\hline & 6 & 47.47 & 21.36 & 24.81 & 20.30 \\
\hline \multirow[t]{2}{*}{ D } & 1 & 39.60 & 22.50 & 30.10 & 19.81 \\
\hline & 6 & 37.57 & 23.12 & 25.91 & 20.43 \\
\hline
\end{tabular}

a These cultures were prepared and treated with maintenance medium in parallel with virus-infected cultures (see Materials and Methods).

${ }_{b}$ Time is measured from the inoculation of the replicate cultures with virus. 
from four representative experiments wherein the cell number and composition with regard to DNA and RNA were determined at two time intervals of the 7-hour experimental period. In order that the characteristics of development of several materials which differ in absolute amount might be compared, the incremental amounts of each at the seventh hour was assigned the value of 100 and the amounts at other times some proportion of 100 . In this form, data concerning the newly formed protein of fraction III of the cytoplasm, the total cytoplasmic RNA, and virus infectivity are plotted in Fig. 1. The synthesis of protein proceeds at a constant linear rate from the first hour until the seventh. It must begin almost immediately since the curve extrapolates to zero time. The synthesis of RNA also begins close upon the initiation of infection and appears to be linear; the rate in the first 4 hours closely parallels that of

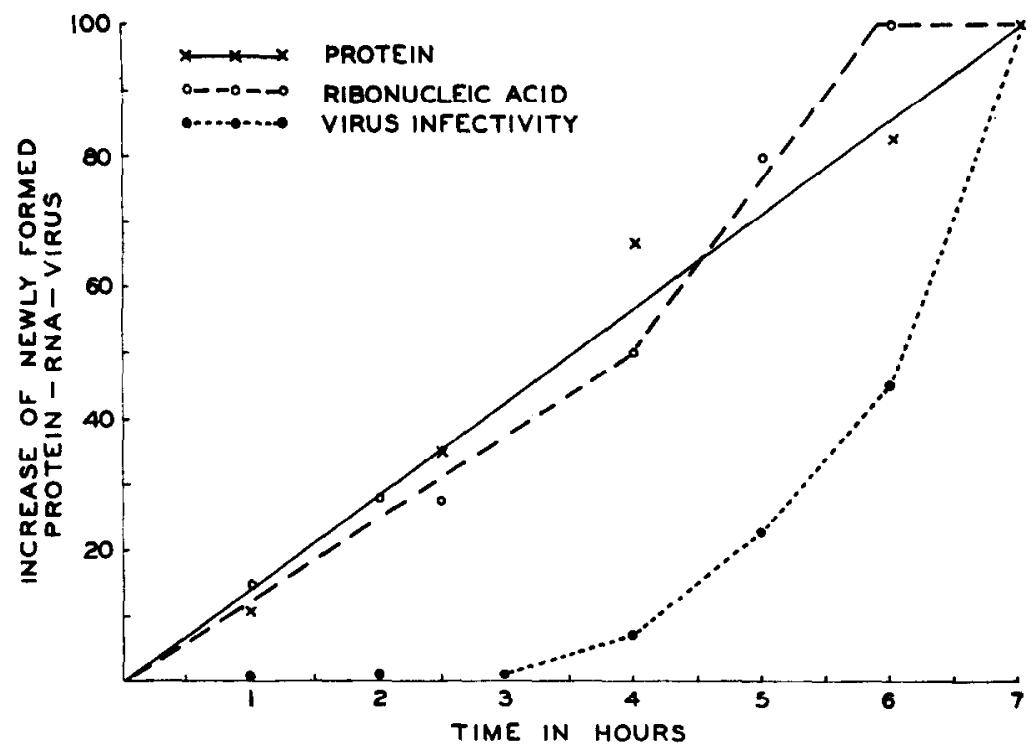

FIa. 1. The increase of newly formed cytoplasmic protein, RNA, and virus in HeLa cells at various times following infection with poliovirus. The newly formed, or $\Delta$, material represents the difference between normal and infected cells in the amount of each material. Values plotted here are expressed as a percentage of the amount of $\Delta$ material found at 7 hours following infection. $x-x-x$ Protein of fraction III of cytoplasm. Values recorded are averages of data from four experiments. $\mathrm{O}--\mathrm{O}--\mathrm{O}$ Ribonucleic acid of total cytoplasm. Values are averages of data from five experiments. Virus infectivity of total cytoplasm. Values are from a single representative experiment. 
the protein synthesis. However, the rate between the fourth and sixth hour, which may also be linear, proceeds at a further increased rate. Unlike the formation of protein and virus activity, the process stops at the sixth hour. It is also of interest that $50 \%$ of the protein and RNA are formed before the appearance of any virus activity. Further, $50 \%$ of the virus appears after synthesis of RNA stops. With the first appearance of virus at the fourth hour, there is an increase in the rate of synthesis of cytoplasmic RNA and a marked decline in the rate of $\mathrm{P}^{32}$ incorporation in the nuclear RNA (Maassab et al., 1957).

\section{DISCUSSION}

The observations related to biochemical morphology recorded in this paper are restricted to the accumulation of large molecules which occurs in various cellular fractions upon infection; for this reason a discussion of the sites of synthetic activity is not appropriate and has been deferred. The term cytoplasmic RNA refers to material found in the cytoplasmic fraction yielded by the aqueous solvent method employed. Of course, other methods using organic solvents or sucrose produce a different fractionation (Brachet, 1957). However, the data obtained using the aqueous solvent method are in agreement with the cytological evidence of fixed and stained preparations which show a marked increase in cytoplasmic basophilia after infection. It is also clear that cytoplasmic accumulation of additional protein and RNA does not result from a redistribution, prior to or during cellular fractionation, of materials present in the cell before infection. There is a net increase in the total protein and RNA of the cell and no significant change in the amount of these materials in the nuclear fraction after infection. Further, the retention of the $\mathrm{P}^{32}$-labeled RNA with high specific activity by the nuclear fraction and the freedom of the cytoplasmic fraction from DNA do not indicate any marked increase in nuclear fragility during the first 7 hours following infection.

The increases in cytoplasmic RNA and protein observed in these experiments are huge to the proportions of the cell. They represent a doubling of the cytoplasmic material in a few hours. There are several lines of evidence which may be meaningful to review in connection with the nature of this newly synthesized material.

First, the yield of virus seldom exceeds 1000 plaque-forming units per HeLa cell. According to Schwerdt and Fogh (1957) the number of characteristic particles in a preparation which are countable with the 
electron microscope is not less than 30 per plaque-forming unit under the best plating conditions. This would set a lower limit of 30,000 particles per HeLa cell. The number of particles per kidney cell was estimated to be in the range of 50 to 300 thousand, or approximately 3 to $5 \%$ of the dry weight of the cell. This increase in cell mass (RNA and protein) actually found at the sixth hour of infection of HeLa cells is of a different order of magnitude. If the incremental RNA were all virus, the yield would be $10^{6}$ particles per cell and the protein would correspond to $10^{7}$ per cell. The discrepancy is emphasized if one considers the cell just before the fourth hour of infection when no increase in viral activity is detectable, but half of the protein and RNA are formed.

Secondly, the distribution of the incremental materials among the various fractions of the cytoplasm does not correspond to the distribution of virus. Further, in two of the fractions the incremental protein and RNA are not present in the same proportions as in the virus. Lastly, the composition of the cytoplasmic RNA is not altered in the direction expected by the accumulation of additional RNA of the virus type. From these considerations, we are led to conclude that the accumulated protein and RNA do not constitute poliovirus and at least in the case of RNA does not represent material of the viral type.

It is possible that the increased rate of RNA synthesis between the fourth and sixth hours of infection represents the synthesis of viral RNA superimposed upon the synthesis of nonviral RNA which began by the first hour and continues through the sixth hour. A further characterization of the soluble protcin fraction of the cytoplasm by serologic techniques is in order. Of interest in this regard is the report of Matzelt et al. (1958) where six glycolytic enzymes, normally in the soluble fraction, were found to increase in HeLa cells infected with poliovirus.

So far each of the fractions of the cytoplasm examined show increases in protein and RNA, and the data suggest that we are observing as a result of infection a hyperdevelopment of cytoplasm without the corresponding nuclear development. The composition of the uninfected control culture is constant on a per cell basis during the experimental period. This could occur in an unsychronized culture which although rapidly synthesizing large molecules is at the same time undergoing cellular division, so as to yield a constant average cellular composition; but this is not the case. These cultures are pretreated for 18 hours with a maintenance medium and during the experimental period the number of cells is not increasing (Table 5). The constant composition results 
from a lack of net synthetic activity in the culture. From this it follows that the action of the virus is not to inhibit nuclear development and allow cytoplasmic development to continue, but rather, the virus induces synthetic activities (albeit normal activities) under environmental conditions which do not allow them to proceed in the normal cell.

The destructive viruses and those eliciting malignancy may share a common activity, namely, the ability to condition certain areas of the cell to synthetic activity. Once this condition is induced, all templates in the affected area including that of the virus may be expected to function. Different viruses containing RNA or DNA would condition different structures and metabolic areas. The report of the hyperdevelopment of DNA of HeLa cells infected with herpes virus is pertinent in this connection (Newton and Stoker, 1958). Since the cell may respond in a limited number of ways, simplicity suggests that the virus can trigger or initiate some one of the stepwise phases that constitute the normal life cycle of the cell. To proceed out of phase might be a terminal activity of the cell or lead to unceasing mitoses.

\section{REFERENCES}

Becker, Y., Grossowicz, N., and Bernkopf, H. (1958). Metabolism of human amnion cell cultures infected with poliomyelitis virus. I. Glucose metabolism during virus synthesis. Proc. Soc. Exptl. Biol. Med. 97, 77-82.

Brachet, J. (1957). Biochemical Cytology. Academic Press, New York.

Dulbecco, R., and Vogt, M. (1954). Plaque formation and isolation of pure lines with poliomyelitis viruses. $J$. Exptl. Med. 97, 167-181.

FIske, C. H., and SubraRow, Y. J. (1925). The colorimetric determination of phosphorus. J. Biol. Chem. 66, 375-400.

Goldfine, H., Koppelman, R., and Evans, E. A., JR. (1958). Nucleoside incorporation into HeLa cells infected with poliomyelitis virus. J. Biol. Chem. 232, $577-588$.

Hogeboom, G. H., and Schneider, W. C. (1955). The cytoplasm. In The Nucleic Acids. (E. Chargaff and J. N. Davidson, eds.), Vol. II, pp. 199-246. Academic Press, New York.

Hurlbert, R. B., Schmitz, H., Bruum, A. F., and Potter, V. R. (1954) . Nucleotide metabolism. II. Chromatographic separation of acid-soluble nucleotides. J. Biol. Chem. 209, 23-39.

Koch, F. C., and McMeekin, T. L. (1924). A new direct Nesslerization microKjeldahl method and a modification of the Nessler-Folin reagent for ammonia. J. Am. Chem. Soc. 46, 2066-2069.

Loh, P. C., Maassab, II. F., and Ackermand, W. W. (1957). Phosphorus metabolism of HeLa cells infected with poliovirus. Bacteriol. Proc. (Soc. Am. Bacteriologists) 57, 138.

Maassab, H. F., Loh, P. C., and Ackermann, W. W. (1957). Growth character- 
istics of poliovirus in HeLa cells : nucleic acid metabolism. J. Expll. Med. 106, 641-648.

Matzelt, D., Homann, J., and Lennartz, H. (1958). Das Verhalten glykolytischer Enzymaktivitäten in Gewebekulturen vor und nach Beimpfung mit Virus. II. Messungen an Gewebekulturen, die mit Poliomyelitisvirus, Type I, infiziert wurden, im Vergleich zu "normalen" Gewebekulturen. Biochem. Z. 330, 260268.

Miroff, G., Cornatzer, W. E., and Fischer, R. G. (1957). The effect of poliomyelitis virus type 1 (Mahoney strain) on the phosphorus metabolism of the HeLa cell. J. Biol. Chem. 229, 255-262.

Newton, A., and Stoker, M. G. (1958). Changes in nucleic acid content of HeLa cells infected with herpes virus. Virology $5,549-560$.

P'ayne, F. E., Kurtz, H., and Ackermann, W. W. (1958). Initial stages of the interaction of HeLa cells with poliovirus. Arch. ges. Virusforsch. 8, 1-15.

Scherer, W. F. (1953). The utilization of a pure strain of mammalian cells (Earle) for the cultivation of viruses in vitro. I. Multiplication of psendorabies and herpes simplex viruses. Am. J. Pathol. 29, 113-126.

Schneider, W. C. (1945). Phosphorus compounds in animal tissues: I. Extraction and estimation of desoxypentose nucleic acid and of pentose nucleic acid. $J$. Biol. Chem. 161, 293-303.

Schwerdt, C. E. (1957). Physical and chemical characteristics of purified poliomyelitis virus. In Cellular Biology, Nucleic Acids and Viruses, Vol. 5, pp. 157165. New York Arademy of Science, New York.

Schwerdt, C. E., and Fogh, J. (1957). The ratio of physical particles per infectious unit observed for poliomyelitis viruses. Virology 4, 41-52.

Volkin, E., and Carter, C. E. (1951). The preparation and properties of mammalian ribonucleic acids. J. Am. Chem. Soc. 73, 1516-1530. 